\title{
How to Define Neuroprotection: The Case of Phenytoin
}

\author{
Keppel Hesselink JM* \\ University of Witten-Herdecke, Germany
}

Submission: January 23, 2018; Published: May 11, 2018

*Corresponding author: Keppel Hesselink JM, Faculty of health, University of Witten-Herdecke, Germany, Email: Jan@neuropathie.nu

Abstract

Phenytoin is recently rediscovered as a neuroprotective compound due to the positive results on structural endpoints in a clinical trial in optic neuritis in multiple sclerosis patients. Data supporting its neuroprotective properties however originated already in the 30 s of last century. The relation between anticonvulsants, the protection of brain tissue and the influence of lack of oxygen on nervous tissue was conceptualized 80 years ago. The concepts 'protection' and 'neuroprotection' have been defined in various of ways and phenytoin was one of the first compounds linked to this concept. However, anno 2018 there still are no neuroprotective compounds registered and available in the clinic. Furthermore, its seems that there is no consensus on definitions for 'neuroprotection'. We discuss literature on the neuro-protective properties of phenytoin and analyze the various approaches and definitions of the concept neuroprotection.

\section{Introduction}

The idea of tissue protection in general and more specifically neuroprotection can be traced back to the 30s of last century. However, the first articles indexed in PubMed, using the keywords 'neuroprotection' or 'neuroprotective' can be found only 50 years later, and thus date from the late 80 s $[1,2]$. Interestingly, after reviewing the literature, it seems that the concept 'neuroprotection' often had and has an implicit container function, understood by all explorers in the field. Still definitions are scarce, although the terms 'protection' and 'neuroprotection' are used widely.

In 2016 phenytoin was proved to have explicit tissue conserving neuro-retino-protective properties in a phase II study in optic neuritis due to multiple sclerosis [3]. This can be regarded as a milestone in 'neuroprotection' research. We explored literature supporting phenytoin's neuro-protective properties and discussed the various ways researchers defined the concepts of 'protection' and 'neuroprotection'.

\section{Period 1: prelude: in vitro models, homogenized brain tissue and cortical slides}

The birth of the concept 'neuroprotection' can be situated around the $30 \mathrm{~s}$ of last century and was linked to the pharmacological activity of the barbiturates, especially related to their anticonvulsive properties. Early studies explored the oxygen consumption in in vitro models, such as in homogenized brain tissue and the influence of barbiturates on that parameter.
At that time is was known that the effect of convulsions on the brain resulted in a reduction of the oxygen. The oxygen consumption (Qo2) was one of the first biological read-outs and was defined as microliter 02 consumed per milligrams dry weight of tissue per hour, according to Warburg (1930); a related read-out such as the respiratory quotient was also used $[4,5]$.

In 1932 it was pointed out by the neurochemist Juda Hirsch Quastel, (1899 -1987) that barbiturates in a model of minced brain tissue, could significantly depress the oxygen uptake, while other anesthetics, such as NO did not. 6 The same was documented when brain slides were used, and the oxygen uptake was reversible suppressed by barbiturates, after removing the barbiturates, oxygen uptake increased again. A second parameter explored was the inhibitory action of anesthetics like ether and barbiturates on the oxidation of glucose or of lactate in minced brain tissue. Barbiturates appeared to be active inhibitors of the brain-oxygen consumption. Quastel assessed the effects of barbiturates, such as phenobarbital in different models, and found that a low dose of phenobarbital inhibited the respiration of cortex slices by $40 \%$ [6].

In these early days schizophrenia was still treated via the induction of convulsions, for instance via the use of the procunvulsant pentylenetetrazol (Metrazol). This method was introduced by the Hungarian-American neurologist and psychiatrist Ladislas J Meduna in 1934. These convulsions led to a reduction of the oxygen saturation of the blood to $42 \%$ [7]. 
In the same period Lennox and Behnke from the Department of Neurology at Harvard University Medical School, pointed out that seizures in epileptic patients can be induced by letting them breath air deficient in oxygen [8]. They are clearly quite sensitive to such oxygen reduction. A convulsion occurred in epileptic patients when the oxygen tension of the respired air was reduced to around $10 \%$, whereas unconsciousness occurs at $7 \%$ or lower in normal persons, without leading to convulsions. Conversely Lennox and Behnke demonstrated that an increased oxygen pressure diminished the number of seizures in an epileptic patient, and their conclusion was: "Decreased oxygen tension tends to precipitate and increased oxygen tension tends to prevent petit mal seizures" [8].

In 1941, in a series of five isolated experiments using a model of a perfused dog head, it was concluded that pentobarbital could reduce both the oxygen and glucose uptake by the brain. Tis led the authors to concluded that barbiturates inhibit the metabolism of the brain [9]. The stage was now set for the introduction of the concept neuroprotection.

\section{Period 2: protection defined as reduction of convulsions}

It seems that the term 'protection' first was used to refer to the reduction of convulsions in models of epilepsy. Pollock and Finkelman sought to find 'protection' against convulsions induced by metrazol in a rabbit model [10]. They introduced the principle 'protective time', the time period of absence of convulsions after an intravenous injection of a certain compound with potential anticonvulsant properties (metrazol), in a pharmacological model of epilepsy. 10 Merritt, Putnam and Bywater, some years later in 1945, discussed various synthetic barbiturate derivatives and used the word 'protection' for the sustained protection against electrical stimulation, by an anticonvulsant drug [11]. Although they did not explicitly define the term 'protection' they clearly referred to the anticonvulsant activity of compounds.

In 1952, the anticonvulsants potency and toxicity of 8 different anticonvulsants in different rodent models were explored. A dose-response experiment was conducted, "between the limits of complete protection or toxicity and no protection or toxicity" [12]. In order to qualify the responses the Protective Index (PI) for anticonvulsants was introduced and defined as the quotient of the desired endpoint in 50\% of animals (ED-50) and the dose eliciting evidence of minimal neurological toxicity in $50 \%$ of animals (TD-50). The Protective Index (PI) was TD50/ED-50. This was the first clear and quantitive definition of the concept protection as the Protective Index [12].

Protection in this period thus was defined related to the reduction or absence of convulsions in models for epilepsy. From now onwards we can identify in literature the concept of the protective action of phenytoin in various papers and models, for instance as its protection against the effect of maximal electroshock [13].

A new indication for phenytoin emerged in the 50s, also related to the concept ofprotection: the prevention of cardiac arrhythmia after myocardial infarction. Harris \& Kokernot [14] in 1950 pointed out that there were similarities between the origins of delayed cardiac ectopic discharges following coronary occlusion and focal epileptogenic discharges [14]. They subsequently suggested that drugs that have proved effect in preventing convulsions, might also suppress ectopic ventricular discharges due to acute myocardial infarction. They could prove that phenytoin $(12.5 \mathrm{mg} / \mathrm{kg} \mathrm{BW})$ produced such complete cessation of ectopic activity. Based on this work and on further observations in the clinic, phenytoin started to be used for its "beneficial protective antiarrhythmic effect" [15].

Zeft et al. [15] explored the protective effect of phenytoin on mortality after experimental myocardial infarction in pigs and found that phenytoin at non-toxic dose could significantly prolong survival time, and so a new parameter based on protection was introduced in the 60s. 15 The 'protective' effect in arrhythmia described in this indication was comparable to the 'protective' effect in convulsions, in both indications the 'protective' effect was against aberrant electrical activity [16].

\section{Period 3: protection defined as extended survival time}

The third period started in the early 60 s of last century with experiments under the guidance of the first professor of anaesthesiology in Denmark, Professor Ole Vilhelm Secher (1918-1993). He explored the influence of barbiturates on the resistance of mice to anoxia, and documented a longer survival time in anoxic mice, anaesthetised with barbiturates compared to unanaesthetised mice, exposed to the same low oxygen concentrations. A depressing action of barbiturates on cerebral oxygen consumption was presumed [17]. Some years later, the protective action of the barbiturate thiopentone against the effects of anoxia was reproduced in a new series of experiments. A number of anesthetics were compared and survival time was most prolonged by the barbiturate thiopental, while some other anesthetics had much less or no effect, ruling out that anesthesia per se was protective. Average survival time was doubled after treatment with the barbiturate $[18,19]$.

In 1964 two neurosurgeons introduced an elegant operation technique in cats via reversible carotid occluding clamps and discussed the best strategies to obtain 'neuroprotection' [20]. If the clamps remained in situ for 10 minutes, all cats died, but when animals were pretreated with sodium pentobarbital $(12-10 \mathrm{mg} / \mathrm{kg} \mathrm{BW})$, the mortality was reduced for more than $60 \%$. Clearly the outcome parameter in this early study on neuroprotection was 'death' or survival'. The authors pointed out that hypothermia could protect tissues from irreversible damage caused by circulatory arrest, but that 'chemical 


\section{Open Access Journal of Neurology \& Neurosurgery}

protection against ischemia 'was a more feasible option. They then discussed three classes of potential protective agents:

A. agents designed to maintain the patency of the vasculature during the ischemia in order to insure complete perfusion of the tissue following its termination,

B. inhibitors of cellular activity that would lower the metabolic demands of the tissue during the ischemia, and

C. physiological compounds, added in excess of their normal concentrations, to forestall the first irreversible changes in the cells.

The authors were quite visionary and were the first in literature to suggest exploring the influence of modulating physiological pathways as ways to protect tissue. This approach has only be realized in the beginning of this age, when the autacoid palmitoylethanolamide was found to be such neuroprotective compound [21].

\section{Period 4: reduction of infarction volume and new surrogate endpoints}

The modern period started in the late 50 s early 60 s and new studies in the field of neuroprotection emerged, focused on the salvation of brain tissue and other tissues using surrogate endpoints to quantify the degree of 'protection'. New surrogate read-outs related to neuroprotection were developed, starting In the late 50s, such as the electrocorticograph and cortical blood flow measurements, based on the delayed clearance of injected krypton-85. Such surrogate endpoints helped to evaluate the neuroprotective efficacy of interventions such as infusions of heparin in stroke models [22,23]

In this same period new experimental infarction models for the brain were developed, based on selective clipping of the middle cerebral artery, for instance using the Mayfield clip [24]. Such procedures became possible due to the development of the operating microscope in the 60 s. In order to quantify the negative impact on brain tissue, volumes of cerebral infarction were measured. In a cat model, following on clipping the middle cerebral artery, the average volume of infarction was $3.73 \mathrm{cc}$. The size of this infarction in survivors however never exceeded a volume of $0.5 \mathrm{cc}$ in size [25]. In experimentally induced cerebral infarctions in a canine model, the administration of pentobarbital, one hour after the arterial occlusion, could significantly reduce infarct volume [26]. Such neuroprotection was also described after administering phenytoin both in animal models, as well as in case series at that time at the clinic of Antonio Aldrete at the University of Colorado School of Medicine, USA [27,28].

A different kind of protective effect at the cellular level was reported in 1972, intraperitoneal applied phenytoin, one hour prior to the intravenous injection of the pancreatoxic compound alloxan, prevents pancreatic beta-cell necrosis [29]. In the same early 70s, it was established that there was an unifying mechanism behind the protective properties of phenytoin: the underlying basis for membrane irritability induced by hypoxia was seen to be relate to the buildup of intracellular sodium concentrations. Phenytoin seemed to have a stabilizing influence on virtually all excitable membranes, via the prevention of this increase of sodium concentration in cells, induced by hypoxia [30].

\section{Discussion}

The concepts 'protection' and 'neuroprotection' have been analyzed in the period since the 30 s of last century up to the recent milestone papers, where fenytoin was found to be retinoprotective in multiple sclerosis patients. 3 We could identify four distinct periods with a different focus on (neuro) protection. During the prelude period (period 1) in the 30s of last century, the anticonvulsant activity of barbiturates and phenytoin started to become well established. In this period researchers used various in vitro models, homogenized brain tissue and cortical slides to document resistance of tissue against anoxic and hypoxic environments. Oxygen consumption (Qo2) was one of the parameters used, however, the term 'protection' or 'neuroprotection' was not explicitly used in this period.The concept neuroprotection can be found in literature from the $40 \mathrm{~s}$ onwards. It was initially linked to protection against convulsions due to anticonvulsants (by barbiturates and phenytoin), and thus was based on a clinical endpoint (period 2). Subsequently, in the early $60 \mathrm{~s}$, in animal experiments it was documented that phenytoin could reduce mortality due to anoxia or hypoxia. The major endpoint in those days pointing to 'protection' was 'survival time' (period 3).

A new era of experimental neurology started around that time, with the emergence of new methods, like the operating microscope entering the laboratory and clinic. Quantitative endpoints based on volumetric measurements of tissue salvation became established (period 4). Protective effects of phenytoin were defined on cellular levels, tissue and organ levels. An unifying hypothesis for the mechanism of action of phenytoin became established, based on its prevention of intracellular sodium increase. Studies on retinoprotection started in the clinic in the early 70s, when the protective effect on clinical endpoints were described for phenytoin in optic neuritis and glaucoma. This led to a recent clinical phase II proof of concept study, supporting phenytoin'sretina-sparing effect in optic neuritis in multiple sclerosis patients.

Neuroprotection has been defined differently since the 30 s of last century, and definitions were linked to effects on physiological and functional parameters, on the levels of cells, tissues and organs, and on the clinical level. As there is consistent evidence in all groups of outcome parameters, it is recommended for further studies to especially focus on structural endpoints,as primary surrogate endpoints, especially since the sensitivity of clinical endpoints is mostly much less compared to these structural 


\section{Open Access Journal of Neurology \& Neurosurgery}

endpoints. Phenytoin has been explored for its properties during a period of 70 years and consistently, throughout times, it was found to be a neuroprotective compound.

\section{References}

1. Silverstein FS, Buchanan K, Hudson C, Johnston MV (1986) Flunarizine limits hypoxia-ischemia induced morphologic injury in immature rat brain. Stroke 17(3): 477-482.

2. Gill R, Foster AC, Woodruff GN (1987) Systemic administration of MK-801 protects against ischemia-induced hippocampal neurodegeneration in the gerbil. J Neurosci 7(10): 3343-3349.

3. Raftopoulos R, Hickman SJ, Toosy A, Sharrack B, Mallik S, et al. (2016) Phenytoin for neuroprotection in patients with acute optic neuritis: a randomised, placebo-controlled, phase 2 trial. Lancet Neurol 15(3): 259-269.

4. Warburg, Otto Heinrich, Frank Dickens (1930) Metabolism of tumours. London, UK.

5. Dickens F, František Šimer (1931) The metabolism of normal and tumour tissue: The respiratory quotient in bicarbonate-media. Biochemical J 25(4): 985.

6. Quastel JH (1939) Respiration in the central nervous system. Physiological Reviews 19(2): 135-183.

7. Himwich, Harold E, Karl M Bowman, Joseph Wortis, Joseph JF (1937) Brain metabolism during the hypoglycemic treatment of schizophrenia. Science 86(2229): 271-272.

8. lennox William G, Albert R Behnke (1936) Effect of increased oxygen pressure on the seizures of epilepsy. Archives of Neurology \& Psychiatry 35(4): 782-788.

9. Handley CA, Morrow Sweeney H, Bruce T Brookman (1941) Metabolism in Perfused Dog's Head During Sodium Pentobarbital Depression ann Metrazol Stimulation. Experimental Biology and Medicine 48(3): 670672.

10. Pollock LJ, Finkelman I (1942) The Action of pyridine and some of its derivatives in preventing experimental convulsions in animals. The Journal of Nervous and Mental Disease 96(4):424-34.

11. Merritt HH, Putnam, Bywater WG (1945) Synthetic anticonvulsants 5, 5-disubstituted hydantoins containing a hetero-atom in the side chain. Journal of Pharmacology and Experimental Therapeutics. 84(1):67-73.

12. Swinyard EA, Brown WC, Goodman LS (1952) Comparative assays of antiepileptic drugs in mice and rats. Journal of Pharmacology and Experimental Therapeutics 106(3): 319-330.

13. Cucinell SA, Koster R, Conney AH, Burns JJ (1963) Stimulatory effect of phenobarbital on the metabolism of diphenylhydantoin. Journal of Pharmacology and Experimental Therapeutics 141(2): 157-160.

14. Harris AS, Kokernot RH (1950) Effects of diphenylhydantoin sodium (Dilantin sodium) and phenobarbital sodium upon ectopic ventricular tachycardia in acute myocardial infarction. American Journal of Physiology-Legacy Content 163(3): 505-516.

15. Zeft HJ, Whalen RE, Ratliff NB, Davenport RD, McIntosh HD (1968) Diphenyl hydantoin therapy in experimental myocardial infarction.
Journal of Pharmacology and Experimental Therapeutics 162(1): 8084.

16. Bassett AL, Bigger JT, Hoffman BF (1970) "Protective" action of diphenylhydantoin on canine purkinje fibers during hypoxia. J Pharmacol Exp Ther 173(2): 336-343.

17. Arnfred I, Secher O (1962) Anoxia and Barbiturates. Arch Int Pharmacodyn 139: 61-14. In the following years some additional results were published.

18. Wilhjelm Bendt J, Ingrid Arnfred (1965) Protective action of some anaesthetics against anoxia. Acta pharmacologica et toxicologica 22(2): 93-98.

19. Wilhjelm BJ (1965) Further investigations into the protective action of anaesthetics against anoxia in mice. Acta pharmacologica et toxicologica 22(2): 131-134.

20. Wright RL, Adelbert Ames (1964) Measurement of maximal permissible cerebral ischemia and a study of its pharmacologic prolongation. Journal of neurosurgery 21(7): 567-574.

21. Esposito E, Cuzzocrea S (2013) Palmitoyl ethanolamide in homeostatic and traumatic central nervous system injuries. CNS Neurol Disord Drug Targets 12(1): 55-61.

22. Denny-Brown D, Meyer JS (1957) The cerebral collateral circulation 2. Production of cerebral infarction by ischemic anoxia and its reversibility in early stages. Neurology 7(8): 567-567.

23. Waltz AG, Sundt TM, Owen CA (1966) Effect of middle cerebral artery occlusion on cortical blood flow in animals. Neurology 16(12): 11851190.

24. Sundt TM, Waltz AG (1966) Experimental cerebral infarction: retroorbital, extradural approach for occluding the middle cerebral artery. Mayo Clin Proc 41(3): 159-168.

25. Sundt TM, Grant WC, Garcia JH (1969) Restoration of middle cerebral artery flow in experimental Infarction. Journal of neurosurgery 31(3): 311-322.

26. Corkill G, Chikovani OK, McLeish I, McDonald LW, Youmans JR (1976) Timing of pentobarbital administration for brain protection in experimental stroke. Surgical neurology 5(3): 147-149.

27. Aldrete JA, Romo-salas FR, Jankovsky l, Franatovic Y (1979) Effect of pretreatment with thiopental and phenytoin on postischemic brain damage in rabbits. Critical care medicine 7(10): 466-470.

28. Aldrete JA, Romo-Salas FR, Mazzia VD, Tan Sl (1981) Phenytoin for brain resuscitation after cardiac arrest: an uncontrolled clinical trial. Critical care medicine 9(6): 474-477.

29. Mennear JH, Gossel TA (1972) Inhibitory effect of diphenylhydantoin on the diabetogenic action of alloxan in the mouse. Diabetes 21(2): 8083.

30. Pincus JH, Grove I, Marino BB, Glaser GE (1970) Studies on the mechanism of action of diphenylhydantoin. Archives of neurology 22(6): 566-571. 
This work is licensed under Creative Commons Attribution 4.0 Licens

DOI: 10.19080/OAJNN.2018.07.555719
Your next submission with Juniper Publishers will reach you the below assets

- Quality Editorial service

- Swift Peer Review

- Reprints availability

- E-prints Service

- Manuscript Podcast for convenient understanding

- Global attainment for your research

- Manuscript accessibility in different formats

( Pdf, E-pub, Full Text, Audio)

- Unceasing customer service

Track the below URL for one-step submission https://juniperpublishers.com/online-submission.php 